\title{
Entre espelhos: a formação em saúde e sua produção de violência
}

\author{
Michelle Cecille Bandeira Teixeira*; Maria Clara Dias**; Carlos Dimas Martins Ribeiro***
}
* Docente, Departamento de Saúde e Sociedade, Instituto de Saúde Coletiva, Programa de Pós-Graduação em Bioética, Ética Aplicada e Saúde Coletiva, Universidade Federal Fluminense
** Docente, Instituto de Filosofia e Ciências Sociais, Universidade Federal do Rio de Janeiro. Programa de Pós- Graduação em Bioética, Ética Aplicada e Saúde Coletiva, Universidade Federal Fluminense
*** Docente, Departamento de Planejamento em Saúde do Instituto de Saúde Coletiva, Programa de Pós-Graduação em Bioética, Ética Aplicada e Saúde Coletiva, Universidade Federal Fluminense

Recebido em 29/12/2017. Aprovado em 28/03/2018.

\begin{abstract}
RESUMO
O objetivo da pesquisa é compreender a ocorrência de violência durante a formação em saúde, quanto à suas origens, grupos vulneráveis e mecanismos pelos quais podem ocorrem tais violências. O estudo dividiu-se em uma etapa de levantamento da literatura sobre a ocorrência de violência na formação em saúde e outra de pesquisa qualitativa, na qual analisou-se um curso da área da saúde - odontologia. Foram feitas entrevistas e grupo focal com estudantes e professores, analisadas por meio da técnica de análise de conteúdo. Os resultados desvelam diversos tipos de violências, caracterizadas como violências interpessoais comunitárias, violência cultural e violência institucional. Conclui-se que tais violências fazem parte da formação em saúde e compõem a construção da identidade destes futuros profissionais de saúde. Tais violências são banalizadas ou naturalizadas, portanto pouco conscientes e de visibilidade não-imediatas. O método empregado foi sensível para captar tais fenômenos e os achados podem colaborar como subsídio para que arranjos institucionais pedagógicos, políticos e curriculares possam atuar sobre isto.
\end{abstract}

Descritores: Violência. Formação Profissional. Justiça Social. Bioética

\section{INTRODUÇÃOO}

A Organização Mundial da Saúde (OMS) ${ }^{1}$ define a violência como o uso de força física ou poder, em ameaça ou na prática, contra si próprio, outra pessoa ou contra um grupo ou comunidade que resulte ou possa resultar em 
sofrimento, morte, dano psicológico, desenvolvimento prejudicado ou privação.

Minayo $^{2}$ prefere abordá-la no campo da subjetividade, o que significa trazer esta discussão para a realidade do cotidiano das pessoas, no espaço micropolítico, mostrando que atinge existências singulares e também coletivas. Violência se associa à dominação, na qual se dá a afirmação de poderes legitimados por uma determinada norma social que lhe confere o controle social. Contudo, faz-se necessário distinguir violência de poder. Para Hannah Arendt $^{3}$, o verdadeiro poder é algo legítimo quando ocorre por meio da argumentação e do diálogo, de forma que se eleja uma representação do coletivo. Já violência é ausência de diálogo, e substituição desta pela força. Outras definições de violência estão presentes na discussão sobre este tema, seja a violência como não reconhecimento ou negação do outro, seja como negação da dignidade humana ou ausência de compaixão. Em todas estas definições, o ponto comum é a falta do sujeito da argumentação, da negociação, negado pela arbitrariedade dos que promovem a violência ${ }^{4}$.

A compreensão sobre violência, suas causas, consequências e relações socioculturais são conteúdos cada vez mais exigidos dentro dos aspectos humanísticos da formação dos profissionais de saúde. Contudo, anterior a isto, devemos nos questionar o quanto a prática da formação em saúde vem, ela mesma, produzindo violências, quais suas origens, os grupos mais vulneráveis e os seus reflexos na formação do profissional que se deseja mais ético e sensível.

Esta rede de interações, que ocorre na universidade, é onde os indivíduos formam e transformam suas identidades e abraçam ou rejeitam ideias. A comunidade discente universitária constrói suas perspectivas de atuação como profissionais, dentro da representação de categoria profissional construída a partir da enculturação de suas características e modos de agir ${ }^{5}$.

Assédio sexual, agressão física e moral no trote, contextos de humilhação e constrangimentos nas relações professor-estudantepaciente além de preconceitos e discriminação são algumas formas de violência que se encontram na formação em saúde. Desta forma, este estudo traz uma análise sobre os diversos tipos de violência que ocorrem na formação em saúde e sua discussão, tendo como referencial os campos da Saúde Coletiva e da Bioética

O objetivo deste estudo foi compreender a ocorrência de violência durante a formação em saúde, quanto a suas origens, os grupos vulneráveis e os mecanismos pelos quais podem ocorrer tais violências.

\section{ABORDAGEM METODOLÓGICA}

$\mathrm{O}$ presente estudo foi submetido e aprovado por Comitê de Ética em Pesquisa (CAAE: 14565613.3.0000.5243).

A pesquisa se dividiu em duas etapas: a primeira compreendeu um levantamento de literatura sobre violência na formação em saúde. Foram buscados artigos, livros, teses e dissertações nos portais PubMed, SciELO e Periódicos CAPES, publicados no período entre 2005 e 2015, utilizando os descritores bullying, preconceito, assédio moral, trote, relação professor-estudante, relação estudante-paciente, formação médica, formação em saúde. A partir dos dados coletados, foi construída uma tabela com a frequência de aparecimento dos tipos de violência nos artigos, cada um caracterizado com exemplos.

A segunda etapa foi um estudo qualitativo que analisou um curso de Odontologia de uma universidade pública. A coleta de dados foi realizada por meio de entrevistas em profundidade com 8 docentes (incluindo a coordenação do curso) e 15 estudantes 
(compreendendo os 3 períodos iniciais e os 3 períodos finais) e um grupo focal com 7 alunas do $7^{\circ}$ período. A intenção foi obter a representação daqueles diretamente envolvidos no processo de formação - estudantes e professores - além de um representante da coordenação de curso. Para determinar o número de participantes, utilizou-se o critério de saturação ${ }^{6}$. Assim, a partir deste número de estudantes e professores, as respostas passariam a ser redundantes com relação aos objetivos da pesquisa. Sendo uma pesquisa qualitativa, não faz sentido o critério de representação quantitativa de amostra para estes grupos, demandados quando almeja-se generalizações ${ }^{6}$. Para que fosse possível identificar estes informantes-chave, recebemos ajuda dos próprios participantes da pesquisa que, ao final da entrevista, já conhecedores do teor das perguntas, indicavam possíveis estudantes ou professores que poderiam dar importantes contribuições para a pesquisa ${ }^{7}$.

As entrevistas foram realizadas mediante utilização de sistema de gravação digital, seguida de transcrição integral para viabilizar a etapa seguinte de categorização dos dados. Os dados foram analisados utilizando a técnica de análise de conteúdo ${ }^{8}$.

\section{RESULTADOS E DISCUSSÃO}

\section{Etapa 1: levantamento na literatura}

Foram encontrados 47 trabalhos científicos que abordaram o tema entre 2005-2015, em diferentes países. Alguns estudos discorrem sobre as consequências disto, desde condições de estresse, depressão dos estudantes e aumento da vulnerabilidade de pacientes da clínica universitária expostos a situações de violência, até a própria reprodução da violência pelos estudantes com colegas, professores e pacientes. A tabela 1 demonstra a frequência de aparecimento dos tipos de violência e exemplos.

Tabela 1. Categorização e frequência de ocorrência de tipos de violência em cursos de saúde no período entre 2005 e 2015, colhidos em levantamento na literatura

\begin{tabular}{|c|c|}
\hline $\begin{array}{l}\text { Tipos de violência e } \\
\text { frequência citada }\end{array}$ & Exemplos descritos nos trabalhos \\
\hline Preconceito $(21,8 \%)$ & $\begin{array}{l}\text { Sexismo, homofobia, racismo, discriminação de classe social e origem } \\
\text { regional, estereótipos de gênero e raça, discriminação de gênero. }\end{array}$ \\
\hline Abuso verbal (20\%) & Intimidação, gritos e agressividade verbal. \\
\hline Assédio sexual $(15,3 \%)$ & Chantagem sexual ou brincadeiras ofensivas com alunas. \\
\hline Violência sutil $(14,1 \%)$ & $\begin{array}{l}\text { Uso de ironia, discriminação disfarçada de brincadeira, } \\
\text { banalização/naturalização/legitimação da violência. }\end{array}$ \\
\hline Desqualificação $(9,4 \%)$ & Rebaixamento moral, desmoralização do estudante. \\
\hline Humilhação $(9,4 \%)$ & Constrangimento, ridicularização. \\
\hline Autoritarismo (7\%) & Falta de diálogo, pedagogia do medo, coação, pressão psicológica. \\
\hline Abuso físico $(3,5 \%)$ & Trote: socos, tapas, empurrões. \\
\hline
\end{tabular}

Chamou a atenção o fato de $76 \%$ dos estudos se referirem à violência na relação professor-estudante. Rios e Schraiber', ao aprofundarem suas análises da relação professor- estudante em um curso de medicina, observaram relações nas quais o professor se coloca como detentor do saber e com poder para subjugar os estudantes ou os pacientes, desencadeando um 
ambiente de tensão, frustração e angústias. Enfatizam que isto está na contramão de propostas de formação orientadas para um perfil mais humanístico de profissional de saúde que tanto se preconiza.

O ensino tanto pode auxiliar a formar sujeitos autônomos e éticos, como pode perpetuar submissões e hierarquias, e denota-se que alguns estudantes reproduzem esta prática de subjugação com seus pacientes ou até com colegas e outros professores que não são autoritários $^{9,10}$.

Existe uma preocupação relatada em grande parte dos estudos deste levantamento sobre a banalização dos diferentes tipos de violência ou da invisibilidade do simbolismo destas violências em uma formação de profissionais de saúde, como comentam diversos autores $^{11,12}$. Estes destacam que, até então, não havia interesse dentro do próprio âmbito universitário em se tratar deste assunto, já que não era considerado relevante o suficiente a ponto de se tornar uma categoria para estudos acadêmicos, contudo isto vem mudando gradativamente, especialmente na violência do trote ${ }^{13}$.

É veemente a necessidade de questionar a responsabilidade das instituições de ensino sobre as questões de violência no ensino universitário em reação a naturalização e banalização, que cria uma cortina de fumaça para uma questão séria dentro da formação em saúde. Dentro de uma perspectiva ética, não é possível admitir conivência ou tolerância com quaisquer tipos de violência durante a formação de profissionais de saúde, uma vez que isso choca-se com o próprio conceito ampliado de saúde ${ }^{11-13}$.

Nenhum dos estudos apontou sugestões para estes problemas, nem no âmbito moral nem no educacional. Os cursos de saúde negligenciam, e ainda não incorporaram estes temas de justiça social para a formação do profissional de saúde.

\section{Etapa 2: análise da pesquisa de campo}

Foram obtidos relatos dos estudantes e professores de um curso de odontologia por meio de entrevistas e grupo focal, observandou-se desde violência física e moral até assédio sexual e convivência em um ambiente sexista. Estas questões são pouco discutidas na formação em saúde, e pretende-se lançar luz em algumas situações que estão, de alguma forma, dificultando a capacidade de manter a integridade física e moral dos estudantes e construindo suas identidades.

Traremos a seguir uma síntese da análise qualitativa das entrevistas, a partir de alguns recortes de relatos coletados que ilustrarão as categorias.

\section{Sobre violência física e desrespeito}

Ao ouvir pouco mais de vinte estudantes, em um universo de aproximadamente 360, tivemos dois diferentes relatos de violência física realizadas pelos professores:

O meu amigo, em uma das clínicas, levou um tapa na mão de uma professora. Ele pegou uma coisa errada, ela (a professora) bateu assim (demonstra batendo na mão e dizendo) não, não pedi isso! Ele até hoje nunca esqueceu isso. (aluno)

[...] teve um professor que agrediu uma aluna. Eu sei que a aluna passou inclusive com 10, porque ela ameaçou de processo, sei lá o quê. Agrediu fisicamente. Porque parece que ela tava fazendo besteira. Não justifica! Ele mandou ela parar e falou que estava indo. A menina não parou, ele foi lá, deu um tapa nela, derrubou tudo e falou: eu mandei parar! (aluna)

Existem diversos desdobramentos que fazem parte desta questão, desde uma formação que preserva uma conformação rígida, pouco 
democrática, que coloca os estudantes como passivos, que recebem o ensinamento do mentor, até abuso de poder alimentado por uma hierarquização das relações que, ao se tornarem autoritárias, não encontram qualquer barreira institucional para frear atitudes desrespeitosas.

A passividade, o lugar de subjugação e hierarquia vistos em muitas situações da relação professor - aluno durante este estudo iniciam assim que a(o) aluno entra no curso, através de um ritual legitimado pela comunidade acadêmica de um modo geral: o trote.

Eu só participei um dia (do trote), porque logo no primeiro dia eu me estressei lá com um menino porque eu disse pra ele que meu cabelo não pode fazer essas coisas, [...] Tacou tinta na minha cabeça e enfiou o negócio no meu ouvido. "Se a gente não quer, você tem que respeitar a gente". (aluna)

Já outros alunos manifestaram percepções mais amenas sobre o trote:

O trote foi tranquilo. Eu tinha a opção de ir embora quando quisesse. (aluna)

É um trote mais pra diversão. (aluno)

Os relatos acima exemplificam diversos depoimentos sobre o trote colhidos durante o campo. Estes depoimentos dividem-se em percepções de violência física e desrespeito e percepções de sentir-se respeitado, sem humilhação e constrangimentos. Este resultado é confirmado com as conclusões de outro estudo em que foi aplicado um questionário aos alunos que deveriam classificar práticas no trote como "brincadeira" ou como "violência". A conclusão é que o que é brincadeira para uns, é violência para outros ${ }^{14}$.

A antropóloga Heloísa Buarque de Almeida ${ }^{14}$ pondera que, em sociedades desiguais como a nossa, rituais de passagem tais como o trote, fortalecem a hierarquia. Então, a primeira regra social encontrada por estudantes é uma regra de submissão. Ainda que seja optativa (os relatos sugerem que o trote é opcional) esta opção é atravessada por subjetividades que estão relacionadas com expectativas, receio de exclusão e legitimação do trote pela universidade que reforça a tradição e o ambiente intimidador, conforme nos colocam Akerman, Conchão, Boaretto $^{11}$

É preciso chamar a atenção para a falta de preocupação dos professores sobre como ocorre o trote que, de fato, é tratado como uma atividade à parte, ao mesmo tempo em que é parte da formação, apesar de não ser visto assim:

Não, não conheço, porque eu tô no nono período, né? Mas eu já ouvi falar [...] Agora aqui eles pedem pra arrecadar dinheiro na rua e eles pintam a pessoa de super herói... De minie... Pinturas bonitas, são legais. (professor)

Grande parte dos professores entrevistados não demonstraram reflexão crítica ou questionadora sobre o sentido e simbolismo do trote, tais como os papéis de subjugação do calouro em relação ao veterano, que é totalmente naturalizado.

Vimos, portanto, que violência física inicia-se no trote, entre alunos, mas ocorre também na relação de professores com os alunos. Tal violência, que não deveria ser tolerada em nenhum grau em uma instituição formadora, está inscrita em uma relação hierárquica e de abuso de poder, a qual precisa ser problematizada na formação em saúde.

\section{Assédio sexual ou desrespeito ao gênero e à orientação sexual}

A violência de gênero contra a mulher tem sido um debate crescente em nossa sociedade. Quando esta violência ocorre dentro das universidades, refletindo um ambiente machista onde a formação universitária tem acontecido, este debate deverá se inscrever em uma pauta de 
responsabilidade ética desta instituição formadora.

Os depoimentos a seguir denotam "brincadeiras" machistas e desrespeitosas que reforçam um estigma de objeto sexual vulgarizado e, muitas vezes, afirmado pela nossa sociedade:

(no trote) As meninas subiam na parte mais alta do DCE e os veteranos em volta, e tinha que falar se você era virgem ou não, para qual veterano você daria, $e$ tinha que apontar, qual posição você mais gosta, perguntas assim. E tinha que falar! Constrangedor! [...] Ah! Da melancia. Eles pegam uma halls e botam na melancia, aí você tem que pegar com a boca. Só que você fica deitada no chão, de bruços e pega a halls com a boca! (aluna)

Eles fazem umas brincadeiras que eu acho muito ridículas, obscenas, enfim! (aluna)

O que significa tolerar um ritual que oscila entre violência e não violência, respeito e não respeito? Um aluno que já estava se formando complementa:

[...] e que a gente tinha que cantar umas músicas de conteúdo sexual, homens $e$ mulheres e, claro, machista para caramba o conteúdo das músicas, e muito neurótico no sentido daquela fissura por sexo, que era uma coisa insustentável.[...]As mulheres eram total vulnerabilizadas nessas brincadeiras, porque era uma brincadeira machista e heterossexual, então eram os homens falando para as mulheres, apesar de eu não me sentir confortável nessa situação. (aluno)

A seguir, o mesmo aluno traz um exemplo dos muitos constrangimentos ocorridos ao longo do curso, causados por um ambiente heteronormativo e novamente machista, que, outra vez, demonstra a questão do ambiente sexualizado e a afirmação de uma imagem estereotipada do corpo da mulher como objeto sexual, durante uma aula:

Eu lembro de um professor que brincou comigo, ele tava falando sobre uma determinada posição do corpo em uma análise laboratorial, ele falou alguma coisa relacionada a bunda, ele usou a palavra bunda, e da forma que ele falou: bunda de mulher, que todo brasileiro gosta de peito e de bunda de mulher. E ele perguntou para mim se eu gostava. Aî eu falei que não, que eu não era heterossexual. Aí ele ficou assim (expressão de assustado). Aí eu falei: "tem mais alguma pergunta, professor?" Aí ele voltou para a aula, não falou mais nada. Eu senti que ele tava forçando a barra, forçando uma piada, forçando uma situação de mau gosto. (aluno)

[...] Por exemplo, essa piada do professor, de peito e bunda, os meninos riam. Era machismo e eles estavam confortáveis com isso. [...] Mulheres são muito vulneráveis na relação interpessoal entre estudantes, mais de objeto sexual, a imagem estereotipada de mulher. (aluno)

Como gay, sempre fui muito militante, mas também existem situações muito humilhantes com relação a esse ambiente sexualizado, machista e heteronormativo. Ainda sinto que existe isso, mas também eu combati muito isso. Existem muitas piadas, muitos momentos constrangedores de brincadeiras nas clínicas. E eu acho justamente que é em decorrência dessa relação de poder extremamente machista [...] $E$ os professores, também nas clínicas, eles 
falam muitas piadinhas com contexto sexual. (aluno)

O relato já traz uma análise bastante elucidativa sobre este quadro que prejudica esta condição de estar livre de assédio sexual e de desrespeito ao gênero e à orientação sexual. E, nestes últimos exemplos, temos isso afirmado pelo ato do professor, como "brincadeiras" que são parte das aulas. As relações veterano-caloura, professor-aluna, desenham o contorno de um poder ocultado por uma naturalização, um tanto invisível aos olhos de quase todos.

Aos olhos da aluna a seguir, não passou imperceptível, quando perguntada se havia situações de assédio sexual, respondeu imediatamente:

Ah! Sim! Acontece (assédio sexual). Estávamos todos assistindo aula, aí estávamos falando de bruxismo, então (uma aluna) falou que ela tá vendo o filme e ela fica rangendo os dentes. Aí o professor falou assim: "Ah, eu posso ver isso pra você, é só você me convidar pra ver um filminho com você". Na frente da turma toda! Aí ela ficou chocada, né? Falou: "Não! O senhor tem que me respeitar!" [...] (e o professor continuou) "Se você quiser a gente vai lá na clínica, mas só se eu puder brincar!" [...]. E ele é sempre assim com todo mundo, com as menininhas mais bonitinhas, então?! Loirinhas e tal, aí que... nossa! Tem uma lá! É muita gracinha. Tanto que faz tanta graça que tudo dela ele faz. [...] você vê que é uma relação diferente! (aluna)

Já as alunas do grupo focal consideram as brincadeiras de conotação sexual algo trivial na relação entre professor e alunas, como coloca uma participante: Dá um molezinho... Em geral uma gracinha... (que os professores fazem) (grupo focal). Ao fazer este relato, a aluna não demonstra qualquer sentimento de indignação ou reprovação, e o restante do grupo não se manifestou diferente.

Estas atitudes são consideradas naturais e até inevitáveis, de acordo com uma professora:

Eu acho que hoje o professor, principalmente eu acho os professores homens mais jovens, bonitos... as meninas, a maioria é de mulheres, porque é a maioria que domina a odontologia, eu acho que eles são bem resistentes. (risos) eu daria nota 10 para eles (os professores)! (professora)

Esta fala desta professora instiga muitos aprofundamentos para compreendermos as consequências da sociedade machista na qual vivemos e que ainda preserva um discurso utilizado não somente por homens, mas também por mulheres, para obscurecer contextos que sempre estão no limite do assédio sexual e, por vezes, estes limites são ultrapassados. Estamos, entretanto, dentro de uma instituição educacional que, além disso, forma profissionais de saúde.

Às vezes, a gente conversa também em conversas informais e o cara fala, elogia atributos, não sei o quê e tal... Até aí tudo bem... acho que se não passar disso, tudo bem. Agora, aproveitar o caráter de vulnerabilidade do outro, aí é grave. Agora, não é só aqui, acho que em todo lugar vai ter sempre alguém com esse perfil. (professor)

Este professor visualiza uma fronteira do que se pode e do que não se pode, fronteira esta que não está baseada em um princípio muito claro. A conversa informal entre os professores sobre atributos das alunas podem virar gracinhas em sala de aula, nas clínicas, nos laboratórios, ou se tornarem assédio sexual através de brincadeiras constrangedoras. Como colocou um aluno, o ambiente é propício ao assédio sexual, e quando o ambiente já está legitimado pelo curso, não falta nada para acumular situações 
contrangedoras e humilhantes, que podem chegar a processos:

Já soube. Acho que tem um professor que foi afastado, sofreu um processo. É um professor que os estudantes diziam que fazia assédio sexual. Acho que ele não está mais. (professora)

Caso que eu ouvi dizer foi professor com aluna. Rolou um processo e tal e outro de assédio moral também, sempre de professor com aluna. (professor)

Há relato, inclusive, de assédio entre professor e uma paciente, que foi "convencida" a não fazer a denúncia:

Um caso que uma determinada paciente queria fazer uma denúncia sobre assédio sexual e aí chamaram as pessoas envolvidas e aí as pessoas chegaram e falaram: deixa isso pra lá, não foi bem assim, aí chegou até a mim e não avançou, mas a paciente queria fazer a denúncia. Foi professor-paciente. Foi convencida a deixar as coisas como estavam. (professor)

Este tipo de violação em relações assimétricas aumenta as vulnerabilidades de gênero e classe social e expõe a universidade a uma deslegitimação de seu papel de formação humana, ética e socialmente justa.

Atitudes com conotação machista e assédio sexual precisam acender o debate sobre os marcadores sociais que produzem desigualdades no interior da formação universitária. E ainda, para a formação de profissionais de saúde, isto se torna uma pauta curricular. Como colocam Marques e colaboradores ${ }^{15}$, vale salientar a dimensão cotidiana destes desrespeitos no interior da formação universitária que, em geral, são tolerados por aqueles que deles participam, especialmente quando envolvem relações assimétricas de poder, originando uma espécie de violência invisível que, na grande maioria das vezes, não chega a ser assumida, verbalizada ou denunciada pelos que dela sofrem.

Diversas vozes, por vezes, expressam constrangimento e indignação por acontecimentos de assédio sexual, de machismo, de ambientes sexualizados e heteronormativos. Por outras vezes, percebe-se a banalização, a naturalização ou a afirmação disto.

\section{CONSIDERAÇÕES FINAIS}

O presente estudo apresentou um recorte das diversas formas de violência que operam em um curso de saúde, como violência física, abuso de poder, falta de respeito ao gênero e à orientação sexual, nas interações desta formação. Grande parte do que foi relatado estava no âmbito cotidiano dos processos pedagógicos, se materializando como brincadeiras, chacotas e comentários que reproduzem um ambiente sexualizado, machista e heteronormativo. Em alguns casos, são manifestações explícitas, mas em sua grande parte, se dão em meio à invisibilidade, tecendo nuanças, mas que deixam suas marcas no que se ensina e como se ensina. Enquanto práticas naturalizadas, prevalecem como parte desta formação.

Observa-se a necessidade de dar luz a esta questão na formação, de modo que este tema faça parte de uma pauta de diálogos entre professores e destes com os estudantes. Uma construção de um olhar crítico sobre estas questões é o que arranjos pedagógicos podem oferecer. $\mathrm{O}$ desafio está em reconhecer um papel de responsabilidade da instituição formadora quanto a estes aspectos.

Cabe aqui discutir pertencimento, reconhecimento, sexismo, machismo, exclusão social e muitas outras coisas necessárias de conhecer como ocorrem no cotidiano. Conhecendo isto, nos abrimos para aprender alteridade, para termos relações mais justas e equitativas e para respeitar a história do outro, em suas diferenças, e apendendo com elas. 


\section{AGRADECIMENTOS}

À Coordenção de Aperfeiçoamento de Pessoal de Nível Superior (CAPES), pela concessão de bolsa de doutorado.

\section{ABSTRACT \\ Between mirrors: Healthcare training and its production of violence.}

The goal of this research is to understand the occurrence of violence during healthcare training, its origins, vulnerable groups and mechanisms by which such violence can occur. The study was divided into a survey of the literature on the occurrence of violence in healthcare training and a qualitative research, in which a course of the health area was analyzed dentistry. Interviews and focus group were conducted with students and teachers and were analyzed through the technique of content analysis. The results reveal several types of violence, characterized as community interpersonal violence, cultural violence and institutional violence. Such violences, it is concluded, are a part of healthcare training and constitutive of the identity construction of these future health professionals. They are trivialized or naturalized, and therefore remain unconscious and of non-immediate visibility. The method used was sensitive to capture such phenomena and the discoveries can collaborate as a subsidy so that institutional pedagogical, political and curricular arrangements are able to act on this matter.

Descriptors: Violence. Professional Training. Social Justice. Bioethics

\section{REFERÊNCIAS}

1. Organização Mundial da Saúde (OMS). Relatório mundial de violência e saúde. Genebra: OMS, 2002. [Acesso em 22 nov. 2017]. Disponível em: https://www.opas. org.br/wp-content/uploads/2015/09/relatoriomundial-violencia-saude.pdf.

2. Minayo, MC. Violência e saúde. Rio de Janeiro: Fiocruz; 2010. 132p.
3. Arendt, H. Sobre a violência. São Paulo: Civilização Brasileira;1999. 167p.

4. Zaluar A, Leal MC. Violência extra e intramuros. Rev Bras Ciênc Soc. 2001; 16:145-64.

5. SiqueiraVHF, Fonseca, MCG, Sá, MB, Lima, ACM. Construções identitárias de estudantes de farmácia no trote universitário: questões de gênero e sexualidade. ProPosições. 2012;23(68):145-59.

6. Fontanella BJB, Ricas J, Turato ER. Amostragem por saturação em pesquisas qualitativas em saúde: contribuições teóricas. Cad Saúde Pública. 2008; 24(1):1727.

7. Vinuto J. A amostragem em bola de neve na pesquisa qualitativa: um debate em aberto. Temáticas. 2014; 22(44):203-220.

8. Bardin L. Análise de Conteúdo. Lisboa: Edições 70; 2008. 281p.

9. Rios IC, Schraiber LB. A relação professoraluno em Medicina - um estudo sobre o encontro pedagógico. Rev Bras Educ Méd. 2012; 36(3):308-16.

10. Cruz GV, Pereira WR. Diferentes configurações da violência nas relações pedagógicas entre docentes e discentes do ensino superior. Rev Bras Enf. 2013; 66 (2):241-50.

11. Villaça FM, Palácios M. Concepções sobre assédio moral: Bullying e trote em uma escola médica. Rev Bras Educ Méd. 2010; 34(4): 506-14.

12. Akerman $M$, Conchão $S$, Barreto $R C$. "Bulindo" com a universidade - um estudo sobre o trote na Medicina. Porto Alegre: Rede UNIDA, 2014.

13. Rego S, Palácios M. Abusos na escola médica. Rev Bras Educ Méd, 2014; 38(4): 417-8.

14. Delgado M. Na mira do trote. Rev Piauí. 2015; 101:32. [Acesso em 22 nov. 2017]. 
Disponível em: http://piaui.folha.uol. Correspondência para: com.br/materia/na-mira-do-trote/. Michelle Cecille Bandeira Teixeira

15. Marques RC, Martins Filho ED, De Paula e-mail: michelle.cecille@gmail.com GS, Santos RR. Assédio moral nas Residências Médica e não Médica de um Rua Benjamin Constant, 35/203 Glória hospital de ensino. Rev Bras Educ Méd. 2012; 36(3):401-6. 